BMJ Open Sport \& Exercise Medicine

\title{
What do Sport and Exercise Medicine (SEM) doctors look like online? A cross- sectional exploration of the social media presence of SEM doctors in the UK
}

\author{
Jonathan Shurlock, ${ }^{1}$ Katherine Marino, ${ }^{1}$ Osman Ahmed ${ }^{2}$
}

\begin{abstract}
To cite: Shurlock J, Marino K, Ahmed 0. What do Sport and Exercise Medicine (SEM) doctors look like online? A cross-sectional exploration of the social media presence of SEM doctors in the UK. BMJ Open Sport \& Exercise Medicine 2018;4. doi:10.1136/ bmjsem-2018-000456
\end{abstract}

Accepted 12 November 2018

Check for updates

(c) Author(s) (or their employer(s)) 2018. Re-use permitted under CC BY-NC. No commercial re-use. See rights and permissions. Published by BMJ.

${ }^{1}$ Faculty of Medicine Dentistry and Health, University of Sheffield, Sheffield, UK

${ }^{2}$ Faculty of Health and Social Sciences, Bournemouth University, Bournemouth, UK

Correspondence to Jonathan Shurlock; jhshurlock@ gmail.com

\section{ABSTRACT}

Objectives To explore the social media presence of Sport and Exercise Medicine (SEM) doctors from the UK. Secondary aims were to identify whether there were any differences in years since qualification or specialisation between those with and without social media profiles and websites.

Methods A cross-sectional design was used to investigate the social media presence of UK-based doctors listed as Fellows of the Faculty of Sport and Exercise Medicine. These SEM doctors were identified via their presence on publicly available member lists. Data collected for each SEM Fellow included the presence of profiles on major social media platforms (Twitter, Linkedln, YouTube and professional Facebook profiles) demonstrated by active profile use and the number of followers/subscribers per platform. The ownership of professional websites and websites hosted by private healthcare providers was also examined.

Results A total of 175 SEM Fellows were identified and included for analysis. Linkedln was the most popular platform for this cohort $(n=115)$, followed by Twitter $(n=73)$, while YouTube had far fewer profiles among the SEM Fellows $(n=9)$. No professional Facebook profiles were identified for the SEM Doctors in this study. Almost a third $(n=49)$ of SEM Fellows did not have a profile on any of the social media platforms examined in this study.

Conclusion Social media is a powerful tool for health promotion and education. The use of these platforms by SEM Doctors and healthcare organisations warrants ongoing guidance and support to enable these practitioners to maximise the utility of these innovative technologies.

\section{INTRODUCTION}

According to the Office of National Statistics, $66 \%$ of the UK population were active users of social media in 2017, compared with $45 \%$ in 2011. ${ }^{1}$ In parallel with this, the use of social media by medical professionals has also grown, with over $90 \%$ of doctors using social media for personal activities. ${ }^{2}$ Increasing acknowledgement is given to the role of social media in healthcare, with its importance recognised for factors such as knowledge

\section{What are the new findings?}

Sport and Exercise Medicine (SEM) doctors in the UK use Linkedln and Twitter more than Facebook and YouTube for professional purposes.

- Surgeons are more likely to own professional websites than those doctors working in medical specialties or General Practice.

- Younger specialists have an increased online presence compared to those who qualified longer ago.

- The SEM Fellow presence on social media is dominated by a small number of high-influence individuals.

How might it impact on clinical practice in the near future?

Sport and Exercise Medicine (SEM) clinicians are using social media platforms to facilitate subsequent clinician interactions.

- An awareness of this provides a pathway for the production of guidance for SEM specialists and their online presence.

translation $^{3}$ and patient engagement. ${ }^{4}$ Related to this, scientific journals are using social media for educational purposes. The British Journal of Sports Medicine (BJSM) is an example of an academic journal that has embraced the power of social media to share ideas and research. ${ }^{5}$

Some of the key concepts embedded in social media, namely sharing and openness, ${ }^{6}$ contrast with the core values of privacy and confidentiality prized by the medical profession. Despite this conflict, it has been accepted that social media, when used wisely, provides a valuable platform for medical professionals. ${ }^{7}$ Engagement from the medical profession may include: keeping up-to-date with best practice recommendations; networking and communicating with patients and peers and promoting positive health behaviours to a wider audience. ${ }^{2}$ The degree and nature of 
Box 1 GMC guidance on Doctors' use of social media

(taken from: https://www.gmc-uk.org/ethical-guidance)

\section{Doctors' use of social media}

Maintaining boundaries

- 10 Using social media also creates risks, particularly where social and professional boundaries become unclear. You must follow the guidance in Maintaining a professional boundary between you and your patient.

- 11 If a patient contacts you about their care or other professional matters through your private profile, you should indicate that you cannot mix social and professional relationships and, where appropriate, direct them to your professional profile.

such engagement is likely to be directly influenced by the individual's scope of practice. The use of social media by doctors, in conjunction with the notable presence of patients on these platforms, suggests that social media will continue to have a place in the landscape of modern medicine.

With widespread use of social media by healthcare professionals comes a concern over its ethical usage. The lack of clarity in distinguishing between personal and professional encounters online is an issue and can result in adverse outcomes for both patients and healthcare professionals. ${ }^{8}$ Examples of healthcare professionals falling foul of their personal online presence include a medical student prevented from continuing training due to comments posted on Facebook ${ }^{9}$ and a surgeon suspended from practice due to a video shared on social media platforms. ${ }^{10}$ There are many examples of the positive use of social media in SEM practice; ${ }^{11} 12$ however, to date, there has not been any investigation into the extent and nature of social media presence in the medical subgroup of SEM.

The differences between personal and professional online presence have been discussed by Ventola, ${ }^{2}$ and the General Medical Council (GMC) in the UK provides clear guidance to its members regarding this distinction (box 1). ${ }^{13}$ While the use of personal and professional websites by doctors may appear more straightforward than their use of social media, website quality is a key factor which influences patient choice ${ }^{14}$ and websites have been shown to directly impact patient engagement and satisfaction. ${ }^{15}$ Aside from the overarching legal guidelines which doctors adhere to, ${ }^{13}$ there is limited specialty-specific social media guidance for SEM professionals who wish to develop their online presence. Currently, the available advice in the SEM domain primarily exists in the form of expert opinion with no evidence-based or data-driven studies in this area. ${ }^{516}$

Sport and exercise medicine (SEM) tends to adapt rapidly to changes in the healthcare environment and adopts new innovations readily. ${ }^{17}$ The use of social media is one such example of this in SEM; however, to date, there has been no exploration of how SEM doctors are using social media or how they have embraced this resource in a professional context.

The aim of this study is to explore the presence or absence of SEM doctors from the UK on major social media platforms. The secondary aims were to identify whether their private jobs, number of years since qualification or their work in a medical or surgical specialty had any association with social media presence. The exploration of this area will enable valuable data to be generated which will inform future work on the precise nature of social media use in this population.

\section{METHODS}

A cross-sectional design was used to provide a snapshot of the current use of social media platforms by SEM doctors in the UK.

\section{Inclusion/exclusion criteria}

Doctors who had achieved Fellow status through the Faculty of Sport and Exercise Medicine (FSEM) were included in this study. Fellows were identified through publicly available member lists from FSEM. ${ }^{18}$ The award of 'Fellow FSEM (UK)' goes to individuals who complete higher specialty training in SEM. Within this cohort, we identified and included only individuals who are currently working in the UK with the intention of providing a representative sample of SEM doctors in the UK. Only doctors who were present on GMC specialty or General Practice (GP) registers were included, in order to ensure current practice and specialist representation. While fellowship accreditation with FSEM is the standard process, it is not an absolute requirement. In order to ensure complete representation, we directly compared the FSEM list of fellows with the GMC specialist register for SEM.

\section{Data collection}

Identification and retrieval of the social media profiles of the included SEM Fellows was completed in a 48 hours period in March 2018 (figure 1). Both websites and profiles on selected platforms were included, in keeping with the widely used definition of social media as a set of 'Internet-based tools that allow individuals and communities to gather and communicate; to share information, $[\ldots]$ and, in some cases, to collaborate'. ${ }^{2}$ Social media platforms which were examined in this study were: Twitter; Facebook; YouTube and LinkedIn. All of these platforms have been shown to be widely used for professional and academic purposes ${ }^{19}$ and are among the most-used websites in the world. ${ }^{20}$ An account was deemed active or in use if there was evidence of user activity in the form of posts, video uploads or user to user interaction. The distinction was made between professional and personal profiles for each platform. A defining criteria was agreed by all researchers as follows; all identified LinkedIn accounts were classified as professional, Twitter and YouTube accounts were deemed professional if the account profile listed the individual's professional 


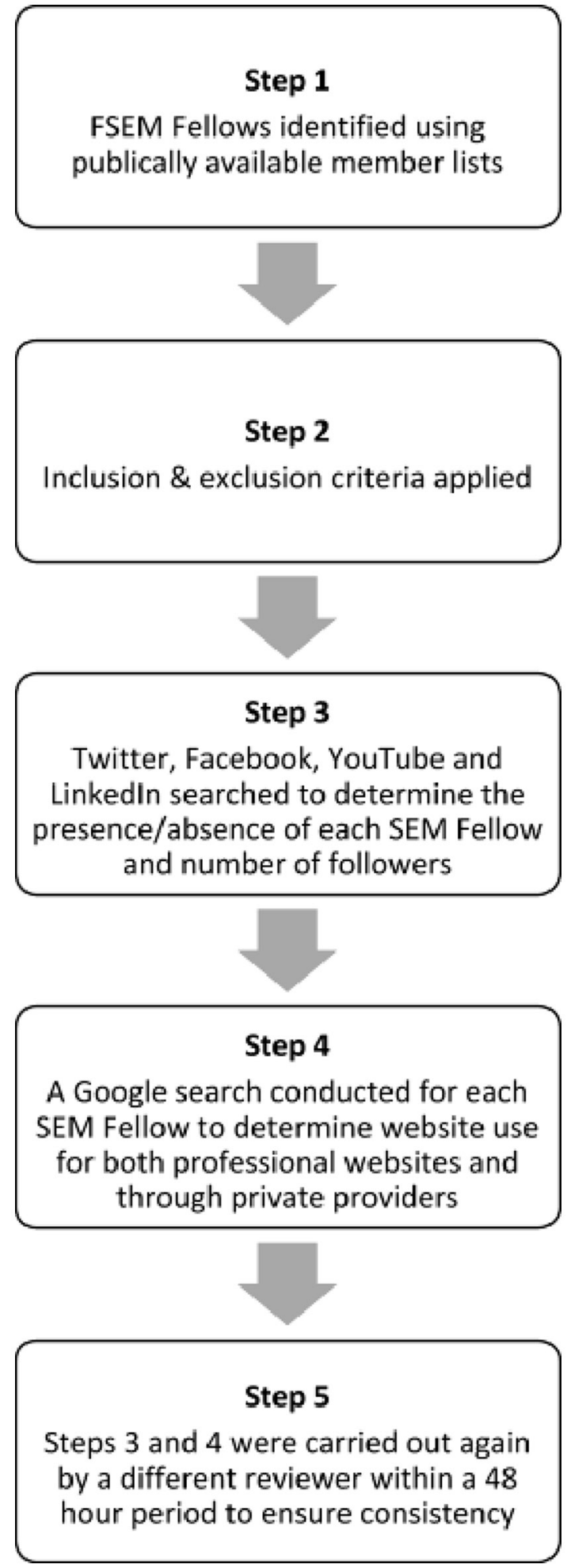

Figure 1 Flowchart outlining the steps taken during data collection. FSEM, Faculty of Sport and Exercise Medicine.

role/s and communications from the account were made primarily in the individual's professional capacity, in keeping with Ventola's, ${ }^{2}$ Facebook accounts listed as business accounts were deemed to represent professional purposes. Any identified personal accounts were excluded from analysis, due to anticipated differences in the professional and personal use of social media.
An online search was carried out to identify each individual SEM Fellow's professional websites. Search terms for this stage included the individual's name and the phrases: 'SEM'; 'Sports and Exercise Medicine'; 'Doctor' and 'FSEM'. The first three pages of search results were reviewed, with professional websites identified as those which were owned by an SEM Fellow. The presence of SEM Fellow profiles on websites hosted by private healthcare providers was searched for in the same manner.

The presence of a profile on each platform and the number of followers for each SEM Fellow was noted. A 'follower' was defined as an individual who has subscribed to a particular profile and receives updates whenever the owner of the profile publishes new content. Where multiple profiles were found for an individual on any one platform, the most recently updated profile was included and used for data analysis. Year of qualification from medical school was identified using the publicly available GMC list of registered medical practitioners. ${ }^{18}$ Each search was carried out by a second reviewer in the same 48 hours period, to ensure consistency. Following the initial search, a discrepancy was found for a single data point, which was corrected following a discussion between both reviewers and repeated search resulting in an inter-rater reliability of 1.00 .

\section{Data analysis}

The Statistical Package for the Social Sciences (SPSS), V.23.0 (IBM Corp, Armonk, New York, USA) was used for statistical analysis. T-tests were used to compare group means, and $\chi^{2}$ tests were used to explore differences in the online presence between surgeons and non-surgeons. Pearson's correlation coefficient was used to explore the relationship between years since qualifying and social media presence.

\section{RESULTS}

Following a review of the FSEM website, ${ }^{16} 235$ Fellows of the FSEM were initially identified. Of these, 47 Fellows were listed as 'overseas' and were excluded from data analysis. Thirteen individuals were neither on a specialty register nor the GP register and were therefore excluded. The remaining 175 Fellows were included for analysis (figure 2).

Almost two thirds ( $\mathrm{n}=115$ or $66 \%$ ) of SEM Fellows were on the specialty register for SEM. The remaining individuals were on the register in seven additional specialties: orthopaedic surgery; GP; radiology; rheumatology; accident and emergency; cardiology and general internal medicine (table 1). The average number of years since entrance onto the GMC register (ie, years since completion of undergraduate medical training) was 25.99 years (range: 9-50). The average number of years since entrance onto the specialist or GP registers was 8.90 years (range: 0-21). 


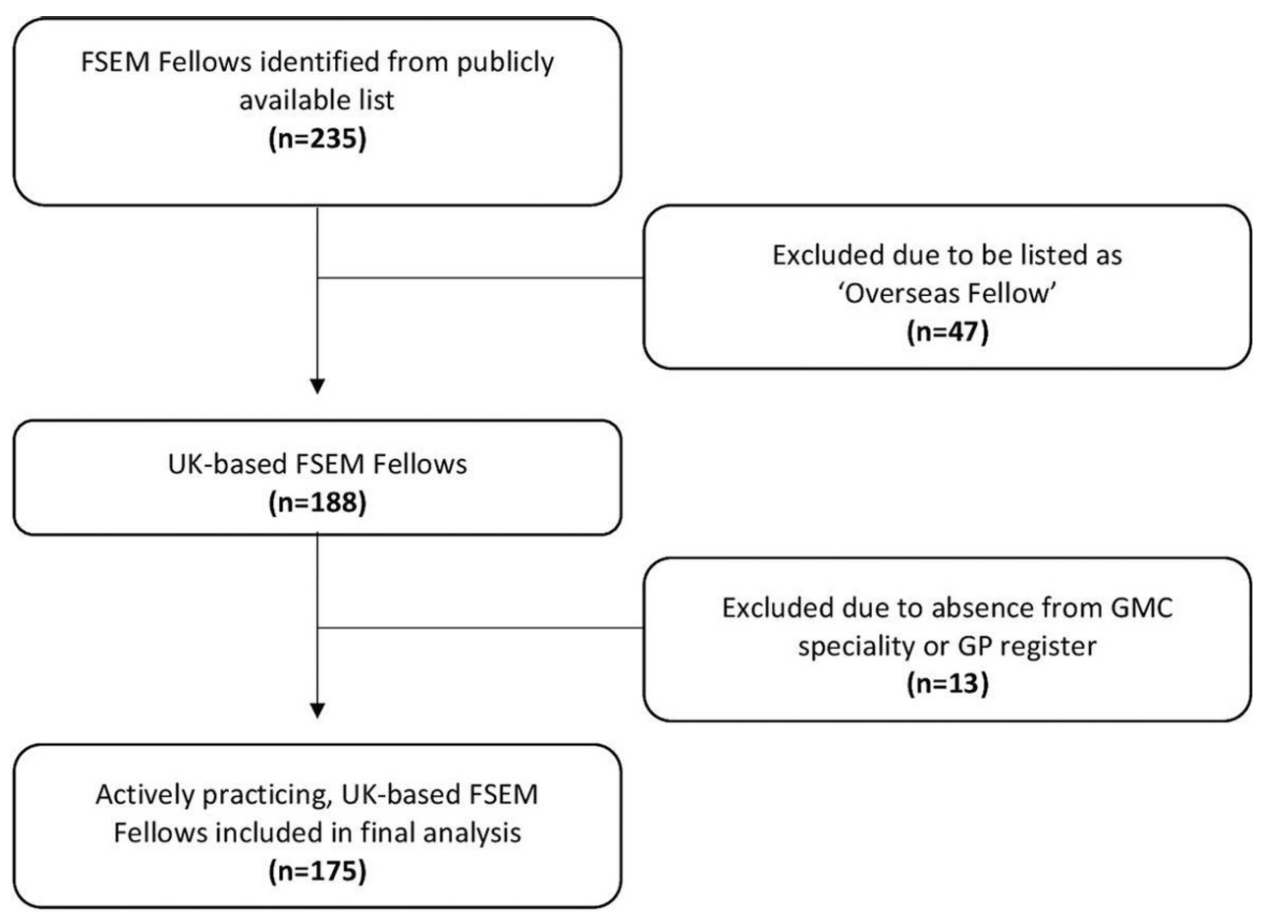

Figure 2 Flowchart outlining the inclusion/exclusion of SEM Fellows. FSEM, Faculty of Sport and Exercise Medicine; GMC, General Medical Council; GP, General Practice.

\section{Social media accounts}

Information related to the use of social media platforms by the included SEM Fellows is shown in table 2. The included SEM Fellows were visible on LinkedIn $(n=115)$, and the average number of LinkedIn connections seen was 550 (range: $0-4318$. Twitter was the second most used social media platform in this study, with 73 SEM Fellow accounts identified. Within these Twitter accounts, the average number of followers was 1348 (range: 0-16 800) and nearly three quarters $(71 \%)$ of the accounts had less than 1000 followers. Nine individuals held YouTube accounts, with an average of 272 subscribers (range: $0-1549$ ). No professional Facebook profiles were identified for the SEM Fellows included in this study.

Almost a third of all SEM Fellows $(n=49)$ had no visible profile on any of the social media platforms included in this study. There was a significant difference in the average number of years on a GMC specialty register between Fellows who did not own a profile on any of the explored platforms and those who owned at least one profile, 10.73 years and 8.16 years, respectively $(\mathrm{p}=0.015$, 2.55 years; $95 \%$ CI 0.51 to 4.59 ). There was a weak, but significant, inverse correlation between the number of years since graduation for the SEM Fellows and their number of social media profiles (Pearson's correlation coefficient: $r=-0.31, p=0.00003$ ).

\section{Website analysis}

Professional websites were identified for $15.43 \% \quad(n=27)$ of the included FSEM Fellows, while over three quarters ( $\mathrm{n}=133$ or $76 \%$ ) had profiles hosted by private healthcare providers. The average number of years that SEM Fellows had been on specialty registers was significantly different between those who owned a professional website and those who did not (mean=11.56 and 8.41 years, respectively; $\mathrm{p}=0.016,3.14$ years; $95 \%$ CI 0.60 to 5.68 ). Of the

Table 1 FSEM fellows subgrouped according to specialist register and their presence on social media platforms

\begin{tabular}{|c|c|c|c|c|c|c|c|c|}
\hline \multirow[b]{2}{*}{ Social media platform } & \multicolumn{8}{|c|}{ Specialty register } \\
\hline & $\begin{array}{l}\text { SEM } \\
\text { (total=115) } \\
N(\%)\end{array}$ & $\begin{array}{l}\text { Orthopaedic } \\
\text { surgery } \\
\text { (total=26) } \\
\mathrm{N}(\%)\end{array}$ & $\begin{array}{l}\text { GP } \\
\text { (total=19) } \\
N(\%)\end{array}$ & $\begin{array}{l}\text { Radiology } \\
\text { (total=5) } \\
\mathrm{N}(\%)\end{array}$ & $\begin{array}{l}\text { Rheumatology } \\
\text { (total=4) } \\
\mathrm{N}(\%)\end{array}$ & $\begin{array}{l}\text { A\&E } \\
\text { (total=3) } \\
N(\%)\end{array}$ & $\begin{array}{l}\text { Cardiology } \\
\text { (total=2) } \\
\mathrm{N}(\%)\end{array}$ & $\begin{array}{l}\text { GIM } \\
\text { (total=1) } \\
N(\%)\end{array}$ \\
\hline Professional website & $16(14)$ & $9(35)$ & 0 & 0 & $1(25)$ & 0 & $1(50)$ & 0 \\
\hline Private healthcare provider website & $98(85)$ & $23(88)$ & $8(42)$ & $4(80)$ & $4(100)$ & $1(33)$ & $2(100)$ & $1(100)$ \\
\hline YouTube & $2(0.02)$ & $5(19)$ & 0 & $0(0)$ & 0 & 0 & $1(50)$ & 0 \\
\hline
\end{tabular}

A\&E, accident and emergency; FSEM, Faculty of Sport and Exercise Medicine; GIM, general internal medicine; GP, General Practice. 
Table 2 FSEM fellows presence on social media platforms and number of followers

\begin{tabular}{lcc}
\hline Platform & $\begin{array}{l}\text { Number of } \\
\text { accounts } \\
\text { N (\%) }\end{array}$ & $\begin{array}{l}\text { Average number of } \\
\text { followers/subscribers } \\
\text { N (range) }\end{array}$ \\
\hline Linkedln & $115(66 \%)$ & $550(0-4318)$ \\
\hline Twitter & $73(42 \%)$ & $1348(0-16800)$ \\
\hline Facebook & 0 & 0 \\
YouTube & $9(0.05 \%)$ & $272(0-1549)$ \\
\hline
\end{tabular}

FSEM, Faculty of Sport and Exercise Medicine.

three most numerous groups of specialists (SEM, Orthopaedic Surgery and GP), surgeons had both the highest proportion of professional websites $(34.62 \%)$ and profiles hosted by private healthcare providers $(88.46 \%)$. Fellows on surgical specialist registers were significantly more likely to own professional websites $\left(\chi^{2} \mathrm{p}=0.003\right)$ compared with those working in medical specialties and GP.

\section{DISCUSSION}

At the time of writing, this is the first study to explore the online presence of SEM specialists. The degree of engagement with social media showed variability across platforms and while few SEM Fellows had professional websites, the majority had online profiles hosted by private healthcare providers. Although not examined in this study, the content hosted on these websites could play a useful role in facilitating the doctor-patient relationship. Rafe and Monfaredzadeh ${ }^{14}$ outlined a qualitative framework to help assess the quality of hospital and medical centre websites, and SEM Fellows with professional websites should consider how they employ these communication channels to best effect.

It is worth noting that over a quarter $(28 \%)$ of included SEM Fellows had no presence on any of the explored social media platforms. Some of the barriers for doctors using social media were explored in the qualitative study of Campbell et al, ${ }^{21}$ where American physicians identified factors including uncertain boundaries in social media use and time pressures. Our study had no direct contact with the SEM Fellows and therefore this could not be explored; however, it may be that these issues also influence SEM clinicians in the UK.

\section{'Unprofessional' Facebook?}

Facebook remains the most widely used social media platform, both in the UK and globally. ${ }^{22}$ Despite the popularity of Facebook in the UK, this study was unable to identify any professional Facebook pages owned by SEM Fellows. It was not within the scope of this work to identify reasons for engagement (or lack of) with each of the social media platforms, although the broader patterns of how each platform is used provides some insight as to why this may be the case. Twitter is widely used by academic institutions, scientific journals, clinicians and academics. Its functionality lends itself to the sharing of academic outputs, helping to translate new knowledge and evidence and in turn drive discussion. ${ }^{23}$ LinkedIn has seen a huge increase in its user base (from 500000 users to 530000000 over a 7 -year period),${ }^{24}$ one of its key intentions is to connect users from a wide range of professional backgrounds. While these platforms have found their respective segments of the academic and professional market, Facebook appears not to have done so for professional purposes among SEM clinicians. The recent scandal involving Facebook and data protection ${ }^{25}$ may deter medical professionals from using the platform to interact with a wider audience, due to concerns over the safety of data on Facebook. Future work will benefit from exploring the truth of this assumption and whether other, unrealised factors play a role in the lack of SEM fellow engagement with Facebook.

\section{Value of social media in surgery}

Individuals on the specialty register for SEM made up the majority of the SEM Fellows included in this study. Those SEM Fellows working in surgical specialties (ie, orthopaedic surgery) were significantly more likely to own professional websites and YouTube accounts when compared with those working in either medical specialties and GP. Given that there is a significant private market for orthopaedic surgeons, this is perhaps unsurprising, as an effective online presence may help to provide a valuable means of advertising in this market. In addition to the sale of services, social media has been shown to be important for surgical specialists for collaboration, patient education and research translation. ${ }^{26}$ The Society of University Surgeons even describe social media as a 'necessary component' of their practice, ${ }^{26}$ and there have been numerous studies exploring the use of social media among surgeons. ${ }^{27-29}$ This indicates that for SEM clinicians involved in orthopaedic surgery, social media is an important consideration in their clinical work.

\section{Cautions of current SEM social media presence}

Findings from our study indicate that a small number of individuals have a substantial numbers of followers. The reasons for this were beyond the scope of this study, but are likely to be multifactorial. Factors such as how SEM clinicians engage with social media, the nature of the positions they hold and their involvement in high-profile events in the public domain (including SEM conferences) may all be factors that confer a large social media reach. While the dominance of a social media platform by a small group of individuals is not inherently negative, there remains the possibility of adverse outcomes from this situation. Online discussions around key clinical areas could be cultivated by these few influential users in such a way that limits debate, by avoiding unfavoured or controversial viewpoints. Whether intentional or unintentional, there are a number of negative implications of this possibility including disenfranchising other specialists from discussion, and thus disengaging them 
from future debate. We see no evidence of this being an issue in the field of SEM at present, but the potential for misuse certainly exists. This potential is only further highlighted by evidence of the use of Twitter to spread disinformation. ${ }^{30}$

\section{Next generation SEM}

A weak but significant inverse correlation was identified between the number of years since graduation for SEM Fellows and their number of social media profiles. Using years since graduation as an approximate measure of the age of the SEM Fellows, this finding suggests that social media presence is greater with younger SEM specialists. This finding is in keeping with broader demographic patterns related to social media use. ${ }^{31}$ This new generation of SEM clinicians, alongside their more established peers, may be able to help harness the use of online means to assist their patients through online interventions. There is an increasing body of work exploring online or 'e-interventions' to support physical activity engagement $^{32-35}$ and SEM clinicians who are confident with these technologies may be in a prime position to facilitate their uptake.

To assist with this, consideration should be given to how SEM clinicians can be best prepared for optimising their online presence in an increasingly digital world. Attempts have been made to embed social media education in undergraduate physiotherapy programmes in the $\mathrm{UK}^{36}$ and undergraduate medical studies in Europe, ${ }^{37}$ but at present there is no SEM-specific training for how to best engage with social media. The creation of an eLearning module to help SEM clinicians better navigate the digital world would be valuable step in this regard, though this has the potential to exclude those individuals who do not engage with online content. Additional personnel or technology support to allow such individuals to access a range of learning formats might serve to enhance professional social media use by SEM specialists. As the use of social media becomes more entrenched in the working lives of SEM clinicians, educating the new generation of clinicians may become a necessity of future medical school training.

\section{Limitations}

Social media engagement is a dynamic feature of SEM practice and its transient nature means there may be changes to the online presence described in this study. It is important to consider that this work focused on UK-based specialists, and that findings within SEM groups in other countries may differ. Measuring the duration of time spent per day by SEM Fellows on each of their social media platforms was not captured by this study, and this may have provided additional information about their degree of engagement with each of the platforms. Although it was not the intention of this study to have direct communication with the SEM Fellows included, future research could employ qualitative methodologies to understand more about the perceived barriers and challenges to SEM Fellows using social media as part of their clinical practice. Such work may in fact reveal that some individuals simply have little interest in maintaining an online presence. This process could also help to identify some of the factors which enable some SEM clinicians to have a large online following.

\section{CONCLUSION}

Social media is a powerful tool for health promotion and education and is a tool which is currently widely used by SEM Fellows in the UK (most notably LinkedIn and Twitter). While the potential for negative outcomes of social media use should be considered, the increased usage of social media by SEM clinicians provides a valuable opportunity to disseminate knowledge and engage patients (including in promoting physical activity). Given that patients have embraced the use of social media for healthcare, SEM organisations and professionals have a responsibility to be aware of these platforms and to adopt their use where appropriate. Ongoing professional guidance and the creation of eLearning platforms for SEM Fellows to better-engage with social media are recommended.

Twitter Follow Jonathan Shurlock J_Shurlock, Katie Marino krmarino1 and Osman Ahmed osmanhahmed.

Contributors JS conceived the design of the study. JS and KM contributed to the collection of the data. JS performed the statistical analysis. All authors contributed to the manuscript writing and approved the final version.

Funding Open Access funding provided by Bournemouth University Open Access fund.

\section{Competing interests None declared.}

Patient consent Not required.

Ethics approval This study was approved by the Ethics Committee of the University of Sheffield, UK.

Data sharing statement Data will be made available on request.

Open access This is an open access article distributed in accordance with the Creative Commons Attribution Non Commercial (CC BY-NC 4.0) license, which permits others to distribute, remix, adapt, build upon this work non-commercially, and license their derivative works on different terms, provided the original work is properly cited, appropriate credit is given, any changes made indicated, and the use is non-commercial. See: http://creativecommons.org/licenses/by-nc/4.0/

\section{REFERENCES}

1. Office for National Statistics. Internet access - households and individuals - office for national statistics [Internet]. Available from: https://www.ons.gov.uk/peoplepopulationandcommunity/hous eholdcharacteristics/homeinternetandsocialmediausage/bulletins/ internetaccesshouseholdsandindividuals/2017\#quality-andmethodology [Accessed 21 Jun 18].

2. Ventola CL. Social media and health care professionals: benefits, risks, and best practices. P T 2014;39:491-520.

3. Bekker S, Paliadelis P, Finch CF. The translation of sports injury prevention and safety promotion knowledge: insights from key intermediary organisations. Health Res Policy Syst 2017;15:1-9.

4. Partridge SR, Grunseit AC, Gallagher P, et al. Cardiac patients' experiences and perceptions of social media: mixed-methods study. $J$ Med Internet Res 2017;19

5. Verhagen E, Bower C, Khan KM. How BJSM embraces the power of social media to disseminate research. Br J Sports Med 2014;48:680-1.

6. Rozenblum R, Greaves F, Bates DW. The role of social media around patient experience and engagement. BMJ Qual Saf 2017;26:845-8. 
7. Bernhardt JM, Alber J, Gold RS. A social media primer for professionals. Health Promot Pract 2014;15:168-72.

8. McCartney M. How much of a social media profile can doctors have? BMJ 2012;344:e440-3.

9. Sims A, 2015. Man posts liam neeson's famous taken quote on facebook, ruins medical career | the independent [internet]. The independant. Available from: https://www.independent.co.uk/ news/uk/home-news/mans-medical-career-ruined-after-postingliam-neesons-famous-taken-quote-on-facebook-a6751451.html [Accessed 22 May 2018]

10. Za'za' B, Chaudhary S, 2018. Famed cosmetic surgeon suspended after indecent video goes viral [Internet]. Gulf news health. Available from: https://gulfnews.com/news/uae/health/famed-cosmeticsurgeon-suspended-after-indecent-video-goes-viral-1.2166197 [Accessed 22 May 2018]

11. Ahmed OH, Schneiders AG, McCrory PR, et al. Sport concussion management using facebook: a feasibility study of an innovative adjunct "iCon". J Athl Train 2017;52:339-49.

12. Vriend I, Coehoorn I, Verhagen E. Implementation of an app-based neuromuscular training programme to prevent ankle sprains: a process evaluation using the RE-AIM Framework. $\mathrm{Br} J$ Sports Med 2015;49:484-8.

13. GMC. Doctors use of social media - GMC [Internet]. Available from: https://www.gmc-uk.org/ethical-guidance/ethical-guidance-fordoctors/doctors-use-of-social-media [Accessed Accessed: 19/6/18]

14. Rafe V, Monfaredzadeh M. A qualitative framework to assess hospital / medical websites. J Med Syst 2012;36:2927-39.

15. Martino SC, Grob R, Davis S, et al. Choosing doctors wisely: can assisted choice enhance patients' selection of clinicians? Med Care Res Rev 2017:107755871774382.

16. Ahmed $\mathrm{OH}$, Weiler $\mathrm{R}$, Schneiders AG, et al. Top tips for social media use in sports and exercise medicine: doing the right thing in the digital age. Br J Sports Med 2015;49:909-10.

17. McCrory P. The reformation of sports medicine. Br J Sports Med 2007;41:281-2.

18. Fellows [Internet]. Faculty of sport and exercise medicine UK. Available from: https://www.fsem.ac.uk/about-us/whos-who/fellowsand-members/ [Accessed Accessed: 14/2/18]

19. Seaman J, Tinti-Kane H. Social media for teaching and learning. Pearson, 2013: 1-32.

20. Alexa Internet, 2018. Alexa top 500 global sites [Internet]. Available from: https://www.alexa.com/topsites [Accessed Accessed: 19/6/18]

21. Campbell L, Evans Y, Pumper M, et al. Social media use by physicians: a qualitative study of the new frontier of medicine. BMC Med Inform Decis Mak 2016;16
22. Statista, 2018. Most famous social network sites worldwide as of September 2017, ranked by number of active users (in millions) [Internet]. The Statistic Portal. Available from: https://www.statista. com/statistics/272014/global-social-networks-ranked-by-numberof-users/ [Accessed 15 Jun 2018].

23. Lang P. Twitter and society. New York, 2014: 399-410.

24. Linkedln Corporation. A brief history of linkedln [Internet]. Available from: https://ourstory.linkedin.com/ [Accessed 17 Mar 2018].

25. Nature. Cambridge analytica controversy must spur researchers to update data ethics. Nature 2018;555:559-60.

26. Steele SR, Arshad S, Bush R, et al. Social media is a necessary component of surgery practice. Surgery 2015;158:857-62.

27. Margolin DA. Social media and the surgeon. Clin Colon Rectal Surg 2013;26:036-8.

28. Vohra RS, Hallissey MT. Social networks, social media, and innovating surgical education. JAMA Surg 2015;150:192.

29. Ralston MR, O'Neill S, Wigmore SJ, et al. An exploration of the use of social media by surgical colleges. Int J Surg 2014;12:1420-7.

30. Vosoughi S, Roy D, Aral S. The spread of true and false news online. Science 2018;359:1146-51.

31. Socia Media Use in 2018 [Internet]. Available from: http://www. pewinternet.org/2018/03/01/social-media-use-in-2018/ [Accessed 21 Jun 2018]

32. Poppe L, Van der Mispel C, De Bourdeaudhuij I, et al. Users' thoughts and opinions about a self-regulation-based eHealth intervention targeting physical activity and the intake of fruit and vegetables: A qualitative study. PLoS One 2017;12

33. Wang ML, Waring ME, Jake-Schoffman DE, et al. Clinic Versus Online Social Network-Delivered Lifestyle Interventions: Protocol for the Get Social Noninferiority Randomized Controlled Trial. JMIR Res Protoc 2017;6

34. Schwarzer R, Warner L, Fleig L, et al. Psychological mechanisms in a digital intervention to improve physical activity: a multicentre randomized controlled trial. Br J Health Psychol 2018;23:296-310.

35. Alley SJ, Kolt GS, Duncan MJ, et al. The effectiveness of a web 2.0 physical activity intervention in older adults - a randomised controlled trial. Int J Behav Nutr Phys Act 2018;15:4.

36. Bournemouth University, 2018. Final year students present innovation projects at conference | bournemouth university [internet] Available from: https://www1.bournemouth.ac.uk/news/2017-0621/final-year-students-present-innovation-projects-conference [Accessed 19 Jun 2018].

37. Mesko B, Györffy Z, Kollár J. Digital literacy in the medical curriculum: a course with social media tools and gamification. JMIR Med Educ 2015;1:e6. 